\title{
Effect of Plasma Enhanced Chemical Vapor Deposition of Tetraethylorthosilicate on the Friction and Wear Loss of Plasma Electrolytic Oxidized Aluminum 6082
}

\author{
Ahmad R Rastkar \\ Laser and Plasma Research Institute, Shahid Beheshti University, Iran
}

Copyright (C) 2015 by authors, all rights reserved. Authors agree that this article remains permanently open access under the terms of the Creative Commons Attribution License 4.0 International License

\begin{abstract}
The surface of 6082 aluminum alloy was coated by plasma electrolytic oxidation (PEO) and then treated by plasma enhanced chemical vapour deposition (PEVCD) of tetraethylorthosilicate (TEOS), oxygen and argon. The PEO electrolyte was alkaline and consisted of potassium hydroxide and sodium aluminates. A pulsed DC power supply with the frequency of $18 \mathrm{kHz}$ was utilized to perform PEO and PECVD treatments. In the PEO process, the electrolyte was at boiling temperature. PECVD was carried out at temperature of $400^{\circ} \mathrm{C}$. The working pressure of vacuum chamber was 10 mbar. The surfaces were characterised using XRD, optical, AFM and SEM microscopy, EDX analysis, Vickers microhardness test and ball on disc wear test methods. The thickness of PEO coated layers was more than $80 \mu \mathrm{m} . \alpha-\mathrm{Al}_{2} \mathrm{O}_{3}$ was the main oxide compound in the coatings. PECVD treatment resulted in the diffusion of silicon in the surface oxide layer. However, up to $16 \%$ silicon was identified in the top surface layers after PECVD treatment, no considerable variation in the thickness of the alumina layer or new layers were observed on the surface of the samples. PEO coating generated very hard surfaces with highly varying coefficient of friction. PECVD treatment reduced the hardness slightly, modified the friction behavior and reduced the wear loss several times.
\end{abstract}

Keywords Adhesive Wear, Surface Roughness, Hardness, Coating, Wear Resistance, Stick-slip

\section{Introduction}

Industrial applications are demanding wear resistant light alloys, such as surface treated aluminum alloys, instead of steel. This requires surface hardness of more than $700 \mathrm{HV}$. Hard anodizing has been experienced as one the methods for improving the surface properties of light alloys. After hard anodizing the surface hardness and the wear resistance of coatings on aluminum are not as high as hard resisting layers on steel [1]. PEO has offered new developments in aluminum oxidation. Several studies have attempted to produce uniform oxide layers on $\mathrm{Al}$ alloys with conventional anodizing or PEO processes in different electrolytes. Nevertheless, researchers have yet to produce a uniform and dense oxide layer free from surface porosities.

Spark discharges in PEO process create discharge channels on the surface of the samples. Melting, oxidation and ejection of the elements in these channels lead to growth of the nano or microcrystalline structure of the coating $[2,3]$. This technique is also named micro-arc oxidation. The plasma phenomena in micro arc oxidation (MAO) or Plasma electrolytic oxidation (PEO) give unique effect to the coatings which increase the life of industrial parts with favorable properties such as high hardness and anti-corrosion abilities $[4,5]$. Industrial applications of these coatings are widely ranging from automotive to aerospace, textile and oil and gas industry [6].

Aluminum oxide coatings do not show low or smooth friction behavior on the surface of aluminum alloys. Sometimes the high coefficient friction or in fact stick slip friction behavior of these coating may result in localized wear or spallation of oxidized surfaces. It has been found that PEO of Al-Si alloy with 7\% silicon content in alkali silicate solution mainly result in the formation of $\alpha-\mathrm{Al}_{2} \mathrm{O}_{3}, \gamma-\mathrm{Al}_{2} \mathrm{O}_{3}$ and $\mathrm{SiO}_{2}$ and some percentage of mullites $\left(3 \mathrm{Al}_{2} \mathrm{O}_{3}-2 \mathrm{SiO}_{2}\right)$ in the coating. These investigations have shown that different combinations of $\alpha-\mathrm{Al}_{2} \mathrm{O}_{3}$ and $\mathrm{SiO}_{2}$ reduce the friction on the alumina surfaces [7]. It is proposed that it would be beneficial to produce mullites like phases or combinations of $\alpha-\mathrm{Al}_{2} \mathrm{O}_{3}$ and $\mathrm{SiO}_{2}$ on PEO surfaces to reduce the friction coefficient of oxide layer and consequently increase the wear resistance of these surfaces.

It has been observed that oxides deposited from organosilicates compounds such as tetraethylorthosilicate (TEOS) show low friction properties on the surface of light alloys. Therefore, in this paper we have studied the effect of 
PECVD of tetraethylorthosilicate (TEOS) for production of low friction compounds on the surface and reduction of the wear loss of PEO coated aluminum alloy 6082.

\section{Materials and Methods}

Cylindrical samples of $5 \mathrm{~mm}$ thickness and $40 \mathrm{~mm}$ diameter were cut from aluminum alloy $6082(0.6 \% \mathrm{Si}, 0.6 \%$ Fe, $0.1 \% \mathrm{Cu}, 0.7 \% \mathrm{Mn}, 0.25 \% \mathrm{Cr}, 0.3 \% \mathrm{Mg}, 0.1 \% \mathrm{Zn}$, remaining $\mathrm{Al}$ ). Two treatments of $\mathrm{PEO}$ and PECVD applied on the samples. Before PEO coating, aluminum samples were cut and ground by $\mathrm{SiC}$ papers to achieve a uniform surface roughness of approximately $6-7 \mu \mathrm{m}$. The samples were degreased with acetone and alcohol and immersed in the electrolyte.

The aluminate electrolyte was prepared from mixtures of $\mathrm{KOH}$ and $\mathrm{NaAlO}_{2}$ in distilled water. A $10 \mathrm{KW}$ pulsed DC power supply was utilized for the application of voltages up to 100,150 and $220 \mathrm{~V}$ and $\max 50$ amps (Table 1). The frequency of the power supply was $18 \mathrm{kHz}$. A 3 liters stainless steel container was used as the cathode. After PEO treatment, the samples were treated by plasma enhanced chemical vapor deposition of tetraethylorthosilicate (TEOS) in a gas mixture argon and oxygen at $400^{\circ} \mathrm{C}$ (Table 1).

Table 1. The conditions of PEO and PECVD treatment of aluminum alloy 6082

\begin{tabular}{|c|c|c|}
\hline Treatment & PEO & PECVD \\
\hline $\begin{array}{c}\text { voltage } \\
\begin{array}{c}\text { Composition of } \\
\text { electrolyte }\end{array}\end{array}$ & $\begin{array}{c}\text { aqueous solution of } \\
10 \mathrm{~g} / 1 \mathrm{NaAlO} 2,5 \\
\mathrm{~g} / \mathrm{l} \mathrm{KOH}\end{array}$ & $-350 \mathrm{~V}$ \\
\hline temperature,${ }^{\circ} \mathrm{C}$ & $\begin{array}{c}\text { Boling point of the } \\
\text { electrolyte }\end{array}$ & $400{ }^{\circ} \mathrm{C}$ \\
\hline Time, min & $\begin{array}{c}10,20,30,40,50, \\
60,90 \text { and } 120\end{array}$ & 60 \\
\hline $\begin{array}{c}\text { The ratio of gas } \\
\text { mixture }\end{array}$ & --------- & $\begin{array}{c}\text { Tetraethylorthosilicate } \\
(\text { TEOS }): O 2: \text { Ar=1:50:15 }\end{array}$ \\
\hline Flow rate of TEOS & ------------- & $4 \mathrm{sccm}$ \\
\hline Flow rate of oxygen & ------------- & $200 \mathrm{sccm}$ \\
\hline Flow rate of argon & ------------- & $60 \mathrm{sccm}$ \\
\hline Pulsed DC power & $1-2 \mathrm{~kW}$ & $300-400 \mathrm{~W}$ \\
\hline
\end{tabular}

The different phases of the coatings were investigated with a Philips X-ray diffractometer (XRD) equipped with $\mathrm{Cu}$ $\mathrm{K} \alpha$ radiation and the scans were performed with $0.02^{\circ}$ step size in the $2 \theta$ range of $20-90^{\circ}$. The microstructure, thickness and topography of the surfaces were studied using optical, scanning electron microscopy (SEM) and AFM. EDX analysis helped to identify the elemental composition of the coatings.

For microscopy studies, the samples were mounted with cold setting resin. The mounted samples were ground using successive grades of silicon carbide emery papers from 80 to 1,200 grit. To achieve a scratch-free surface, the ground samples were finally polished using $0.05 \mu \mathrm{m}$ alumina powder. Kroll's chemical reagent was used to reveal the microstructure of the samples.

The microhardness of the coating layers was measured in different places by a Vickers microhardness test machine. The cross section profile of the wear tracks was measured by a DEKTAK profilometer. The friction and wear tests were performed in a ball on disk configuration under normal loads of 5 and $30 \mathrm{~N}$ at $0.1 \mathrm{~m} / \mathrm{s}$ speed for maximum $350 \mathrm{~m}$ sliding distance. The volume loss of the samples was measured by multiplying the diameter of the wear tracks to the area of the cross section of the wear tracks.

\section{Results and Discussions}

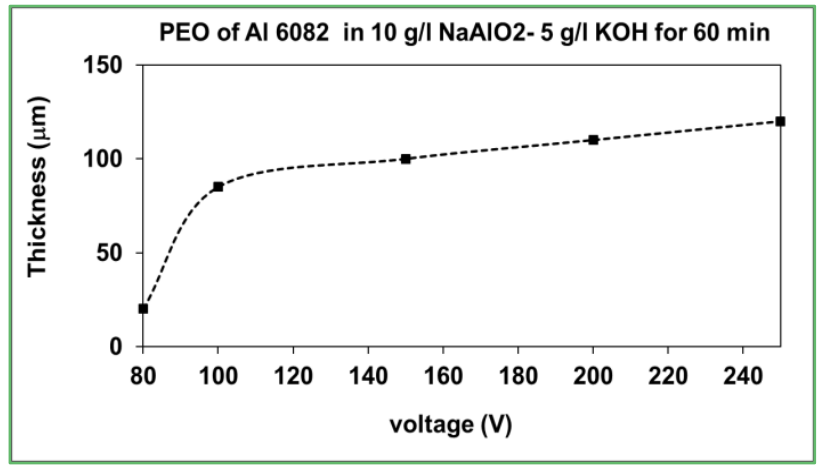

(a)

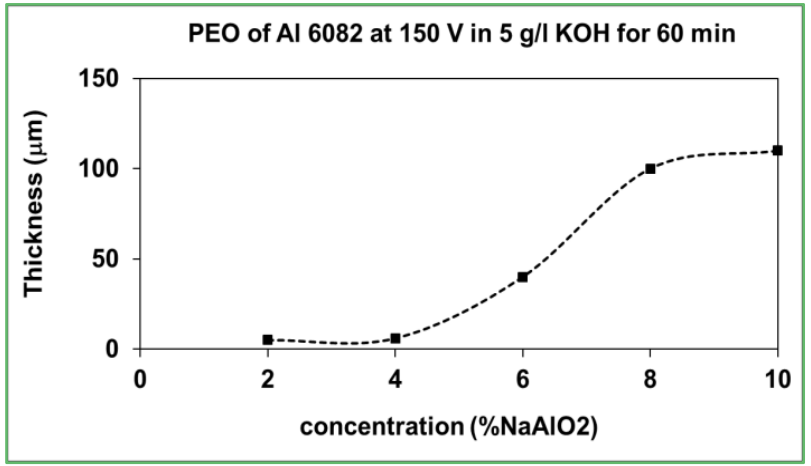

(b)

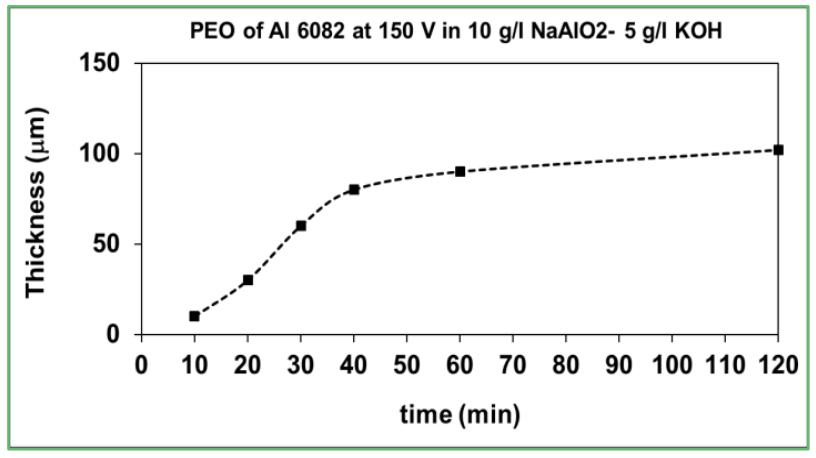

(c)

Figure 1. Graphs show (a) the effect of voltage at constant concentration and time, (b) the effect of $\mathrm{NaAlO}_{2}$ concentration at constant voltage and time and (c) the effect of time at constant voltage and concentration on the thickness of PEO oxide layers. 
The early experiments of PEO coatings showed that at voltages less than $100 \mathrm{~V}$ the coating is very thin and at voltages higher than $150 \mathrm{~V}$ does not increase strongly (Figure 1a). The least effective amount of $\mathrm{NaAlO}_{2}$ was 10 percent. The higher percentages of $\mathrm{NaAlO}_{2}$ did not dissolve properly in the aqueous solution and did not increase the thickness of the coating significantly (Figure 1b). After 60 min PEO coating, the approximately linear growth rate of the oxide layer was very low and did not increase considerably (Figure 1c). Therefore the samples treated at $150 \mathrm{~V}$, for 60 min in aqueous solution of $10 \mathrm{~g} / 1 \mathrm{NaAlO}_{2}$ and $5 \mathrm{~g} / \mathrm{KOH}$ were selected for further investigation in this paper.

\subsection{Microstructure}

The PEO process generally resulted in porous layers on the surface of 6082 aluminum alloy. The PECVD of tetraethylorthosilicate (TEOS) in Argon and Oxygen mixture did not change the appearance and thickness of the surface layers significantly. It has frequently observed that deposition of TEOS by PECVD treatment has resulted in very thin layers on different substrates. However, the thin layers were very scratch resistant [8].

Figure 2 shows two samples treated with successive PEO and PECVD processes. These samples were plasma electrolytic oxidised in an aqueous solution with concentration of $10 \mathrm{~g} / 1 \mathrm{NaAlO} 2$ and $5 \mathrm{~g} / \mathrm{l} \mathrm{KOH}$. As seen in the Figure 2a, the thickness of the sample coated by PEO at voltage of $100 \mathrm{~V}$ and then deposited by PEVCD of TEOS was less than $10 \mu \mathrm{m}$. Also, some debris exists on the surface which may belong to any top surface layer that separated during metallography of the samples.

Figure $2 \mathrm{~b}$ shows another sample that PEO coated at $150 \mathrm{~V}$ and then deposited by PECVD of TEOS at $400^{\circ} \mathrm{C}$. This coating has small porosities and no distinct layers are observed in the sample. The thickness of the oxide compound layer was around 85 um (Figure 2a). Some porosity can be observed on the cross section of the surface layer. However there is not a big variation in the structure of the fine grains of the oxide compound layer.

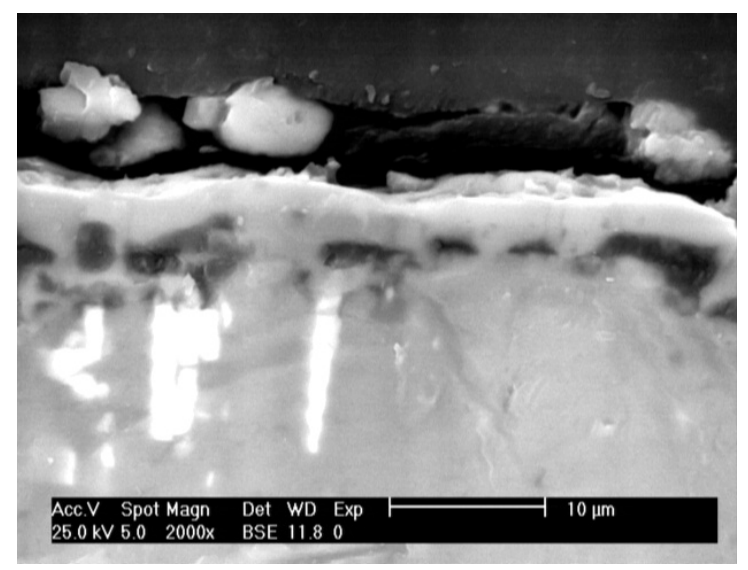

(a)

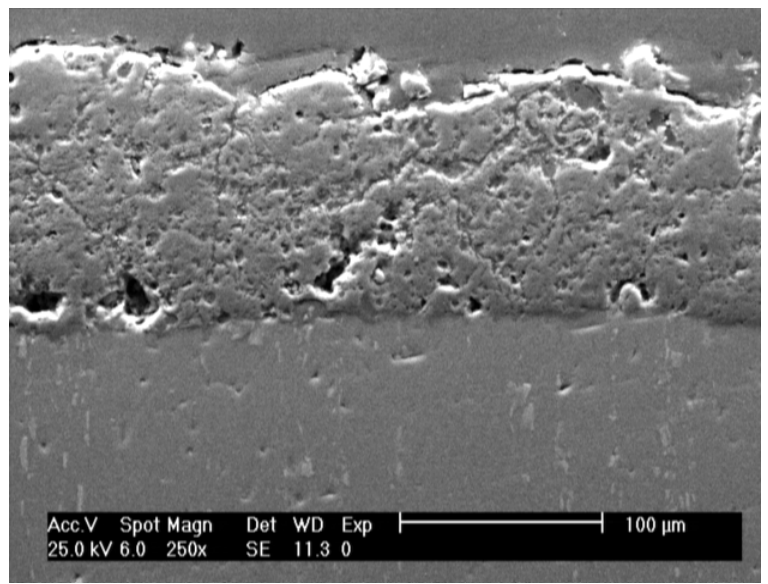

(b)

Figure 2. SEM micrographs of the sample plasma electrolytic oxidised in aqueous solution of $10 \mathrm{~g} / 1 \mathrm{NaAlO}_{2}$ and $5 \mathrm{~g} / 1 \mathrm{KOH}$ for $60 \mathrm{~min}$ at (a) $100 \mathrm{~V}$ and at (b) $150 \mathrm{~V}$, followed by PECVD of TEOS for $60 \mathrm{~min}$ at $400^{\circ} \mathrm{C}$ for both (a) and (b).

It is proposed that the layer deposited by PECVD of TEOS has been very thin to be observed in the top surface of the PEO coated surface.

The layer deposited from TEOS may have been integrated in the top layers. The incorporation of silicon in the top surface layer was later identified by EDX analysis.

\subsection{Phase Identification}

XRD of aluminum alloy 6082 (Figure 3a) showed only four distinct peaks in the pattern in which (311) peak was very strong. After PEO treatment, peaks of $\alpha-\mathrm{Al}_{2} \mathrm{O}_{3}$ and $\gamma-\mathrm{Al}_{2} \mathrm{O}_{3}$ were identified in the XRD pattern (Figure $3 \mathrm{~b}$ ).

However, small peaks of Aluminum alloy 6082 were also observed in the pattern. It can be attributed to the thick layer of $\alpha-\mathrm{Al}_{2} \mathrm{O}_{3}$ that has prevented the enough penetration of $\mathrm{X}$-ray into the aluminum substrate. Consequently the peaks of the oxide layer have appeared stronger in the patterns. Also, as seen in Figure 3b, the peaks of $\alpha-\mathrm{Al}_{2} \mathrm{O}_{3}$ are much stronger than $\gamma$-alumina. This is strongly related to the higher amount of $\alpha-\mathrm{Al}_{2} \mathrm{O}_{3}$ than that of $\gamma$-alumina. It has been reported that the $\gamma$-alumina phase prevails in the early stage of the PEO process, and the $\gamma \rightarrow \alpha$ phase transition occurs in those layers that are thicker than 30-40 $\mu \mathrm{m}$ [1].

PECVD treatment did not result in any distinctive peaks of $\mathrm{SiO}_{2}$ (Figure 3c). This is correlated to the very thin layers of $\mathrm{SiO}_{2}$ or dissolved $\mathrm{SiO}_{2}$ compound in the top layers of $\alpha-\mathrm{Al} 2 \mathrm{O} 3$ layers. Many investigations in the field of $\mathrm{SiO}_{2}$ deposition from PECVD of TEOS and oxygen have produced a few microns or very thin layers of $\mathrm{SiO}_{2}$ on different substrates. These thin layers have been identified mostly by FTIR or Raman spectroscopies and have not been shown by XRD analysis $[9,10]$. From another hand, the peak positions of aluminosilicate or mullites compounds such as $\left(3 \mathrm{Al}_{2} \mathrm{O}_{3}, 2 \mathrm{SiO}_{2}\right)$ in the XRD patterns have the same position as $\alpha-\mathrm{Al}_{2} \mathrm{O}_{3}[11,12]$. 


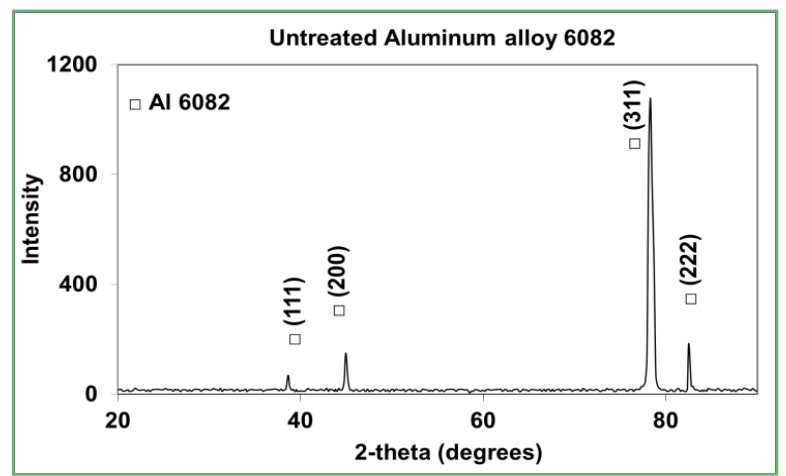

(a)

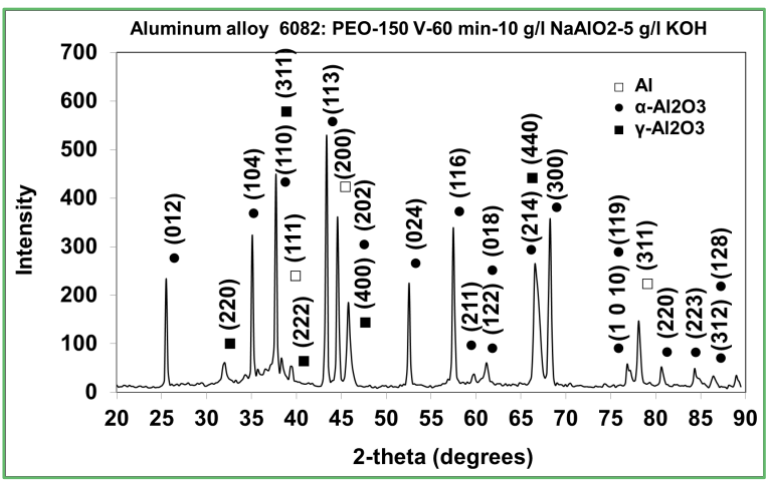

(b)

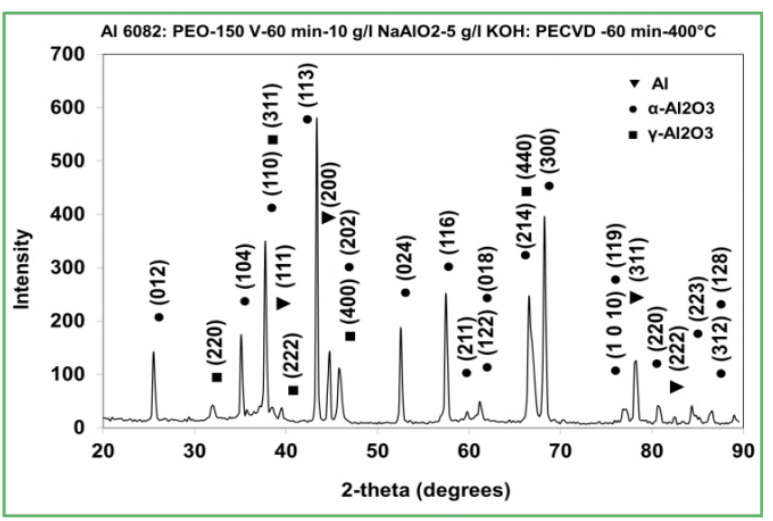

(c)

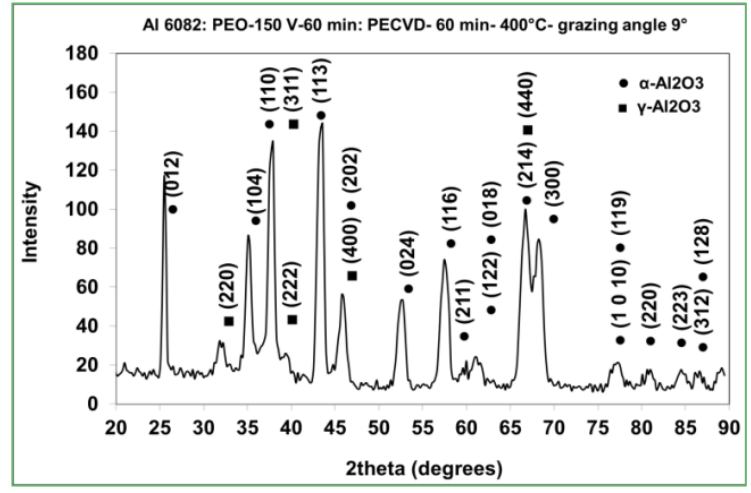

(d)

Figure 3. XRD patterns of (a) untreated Aluminum alloy 6082, (b) Aluminum alloy 6082 , PEO treated at $150 \mathrm{~V}$ for $60 \mathrm{~min}$ in aqueous solution of $10 \mathrm{~g} / 1 \mathrm{NaAlO}_{2}$ and $5 \mathrm{~g} / 1 \mathrm{KOH}$, (c) the treatment as (b) and then PECVD treated for $60 \mathrm{~min}$ at $400^{\circ} \mathrm{C}$ and (d) the same as (c) at incident grazing angle of 9 degree.
EDX spectra of three regions on PECVD treated sample showed on average $16 \%$ silicon in addition to aluminum and oxygen. The higher content of aluminum and oxygen than that of silicon suggested that the amount of $\alpha-\mathrm{Al}_{2} \mathrm{O}_{3}$ in the coating was in excess of $\mathrm{SiO}_{2}$. Therefore it may be concluded that the deposition of TEOS by PECVD has resulted in very thin $\mathrm{SiO}_{2}$ layers or a compound that integrated or mixed with $\alpha-\mathrm{Al}_{2} \mathrm{O}_{3}$ during the formation process of the surface layers $[13,14]$. Grazing angle XRD of PECVD treated sample showed only peaks of $\alpha-\mathrm{Al}_{2} \mathrm{O}_{3}$ (Figure $3 \mathrm{~d}$ ). As seen in Figure $3 \mathrm{~d}$, there was not any peak of aluminum alloy and the peaks of $\gamma-\mathrm{Al}_{2} \mathrm{O}_{3}$ did not appear in the pattern. It can be concluded that the top surface layers have been modified with PECVD treatment and any layer of silicon compound has been very thin or dissolved in the top layers.

\subsection{Surface Topography and Roughness}

Surface morphology of the coatings after 60 min PEO treatment at 100, 150 and $220 \mathrm{~V}$ is shown in Figure 4. It can be seen that PEO coating at $100 \mathrm{~V}$ (Figure 4a) has resulted in deep and fine gained porosities on the surface that have broken out of the surface. This kind of surface roughness may be correlated to the less violence created in voltage of $100 \mathrm{~V}$ in comparison with higher voltages. These pores are actually residual discharge channel during the spark reaction. The irregular-shaped areas around discharge channel are formed due to the rapid cooling effect of the electrolyte [15]. At $150 \mathrm{~V}$, SEM examination on the top surface of the specimen revealed the sink-hole type of pores in the discharge channels which are clear on the surface (Figure $4 b)$.

These porous structures can be useful in keeping the lubricants at the sliding surfaces and less friction coefficient. At $220 \mathrm{~V}$, the surface irregularity has increased and pores of sink-hole type have grown outward and varied to round type protrusions out of the surface. This type of surface roughness did not expect to have low coefficient of friction. After PECVD treatment of the PEO coated sample at $150 \mathrm{~V}$, the surface did not changed strongly and some pores were filled with the compounds deposited from TEOS organometallic compound. This surface topography expected to improve the friction behavior of the material.

To evaluate the average surface roughness of treated surface, untreated aluminum alloy 6082, PEO treated sample at $150 \mathrm{~V}$ in aqueous solution of $10 \mathrm{~g} / 1 \mathrm{NaAlO} 2$ and $5 \mathrm{~g} / \mathrm{KOH}$ for $60 \mathrm{~min}$ and the sample PECVD treated for $60 \mathrm{~min}$ at $400^{\circ} \mathrm{C}$ after PEO treatment were examined by AFM microscopy (Figure 5).

As seen in Figure 5, the untreated material had an average roughness of $6.88 \mu \mathrm{m}$ (Figure 5a) and increased to $12.5 \mu \mathrm{m}$ by PEO coating (Figure $5 b$ ).

This is quite reasonable in PEO process. In this process the microdischarges take place over a very short time interval and quench very quickly that result in rough surface. This is in agreement with SEM micrographs from PEO coated surfaces (Figure 4). 


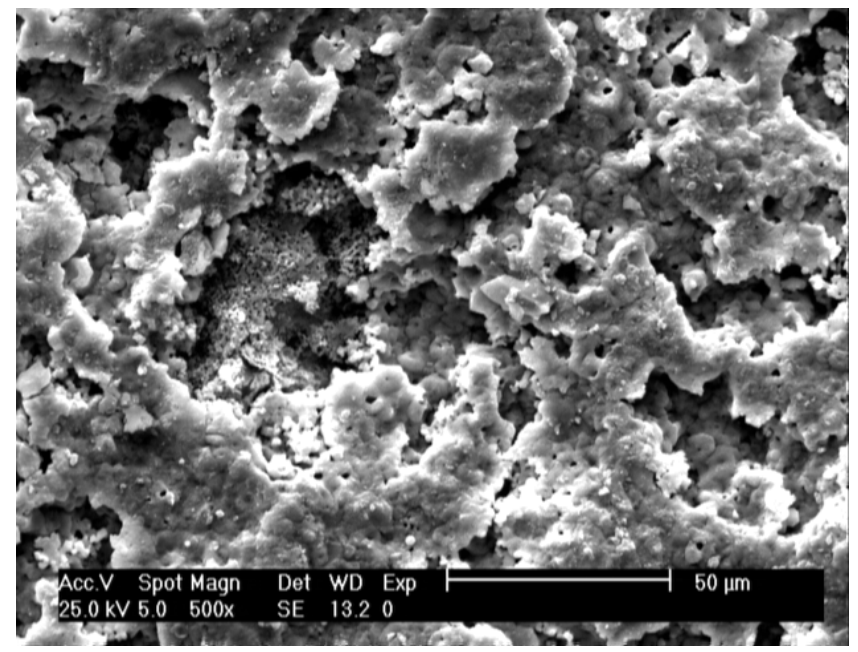

(a)

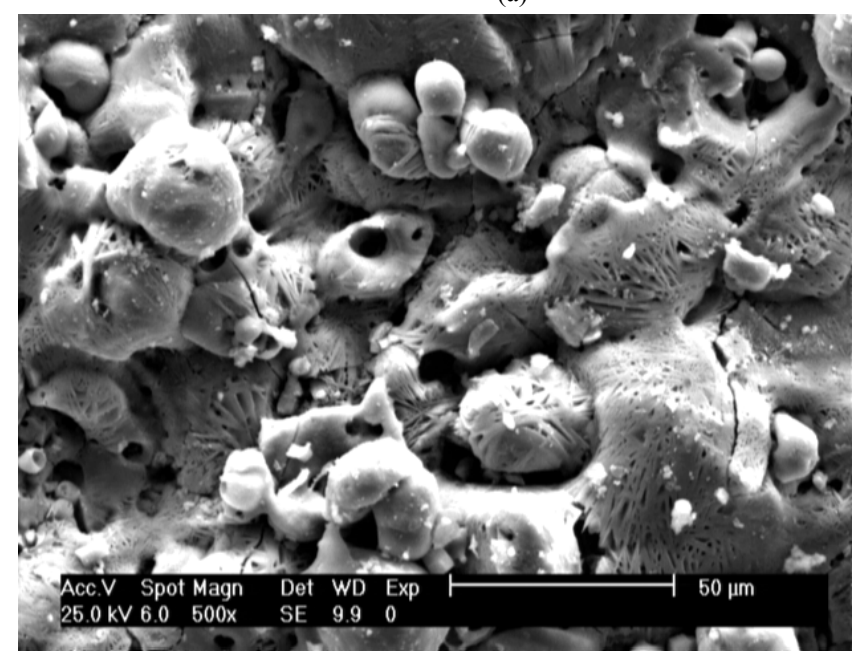

(c)

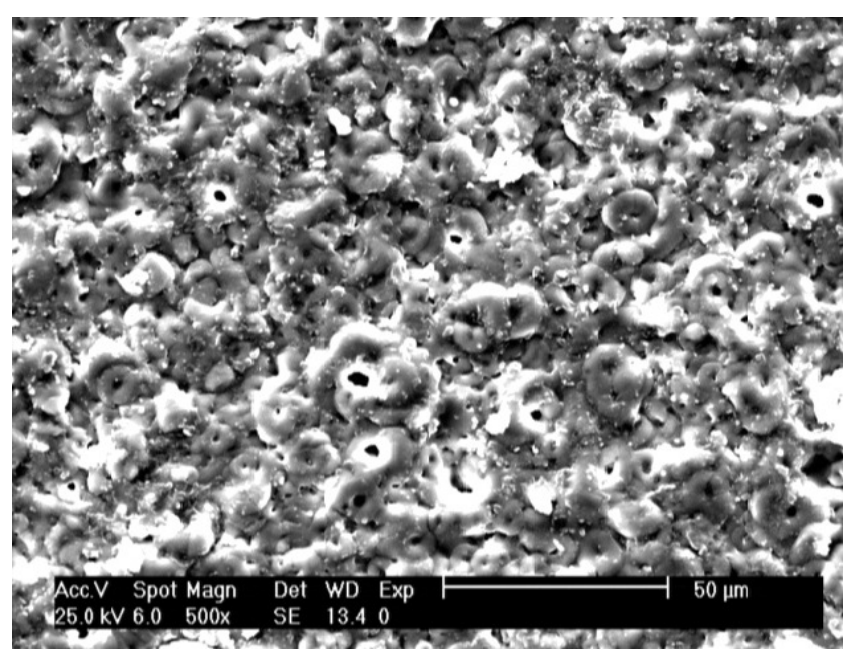

(b)

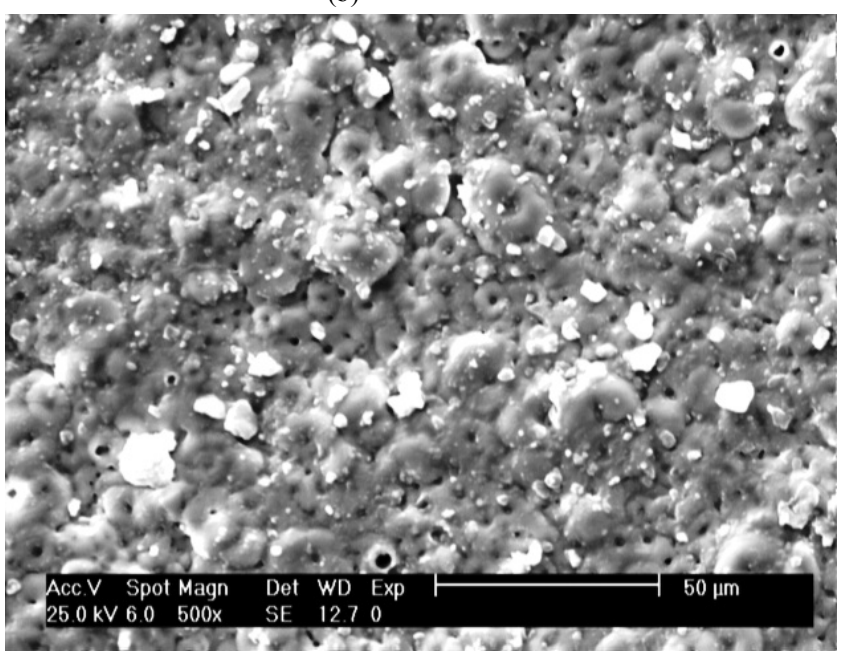

(d)

Figure 4. SEM micrographs of surface topography of the samples plasma electrolytic oxidised at (a) $100 \mathrm{~V}$, at (b) $150 \mathrm{~V}$, at (c) $220 \mathrm{~V}$ at for $60 \mathrm{~min}$ in aqueous solution of $10 \mathrm{~g} / 1 \mathrm{NaAlO}_{2}$ and $5 \mathrm{~g} / 1 \mathrm{KOH}$ and (d) the same as (b) followed by PECVD of TEOS for 60 min at $400^{\circ} \mathrm{C}$.

After PECVD process the average roughness decreased to $4.81 \mu \mathrm{m}$ (Figure $5 \mathrm{c}$ ) which is less than that of the untreated material. It may be suggested that PECVD treatment had produced some compounds that have diffused into some pores and reduced the average surface roughness [11].

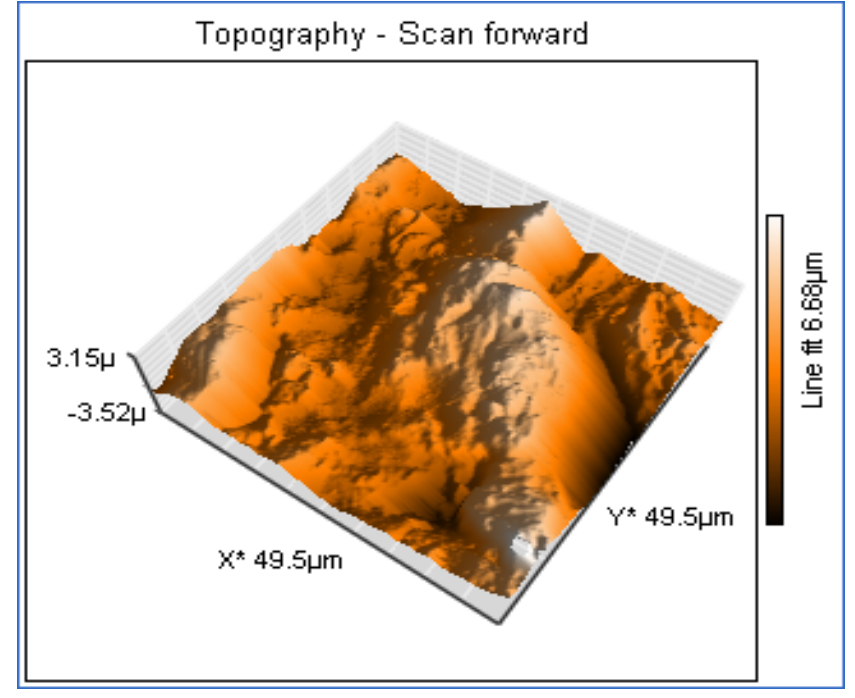

(a)

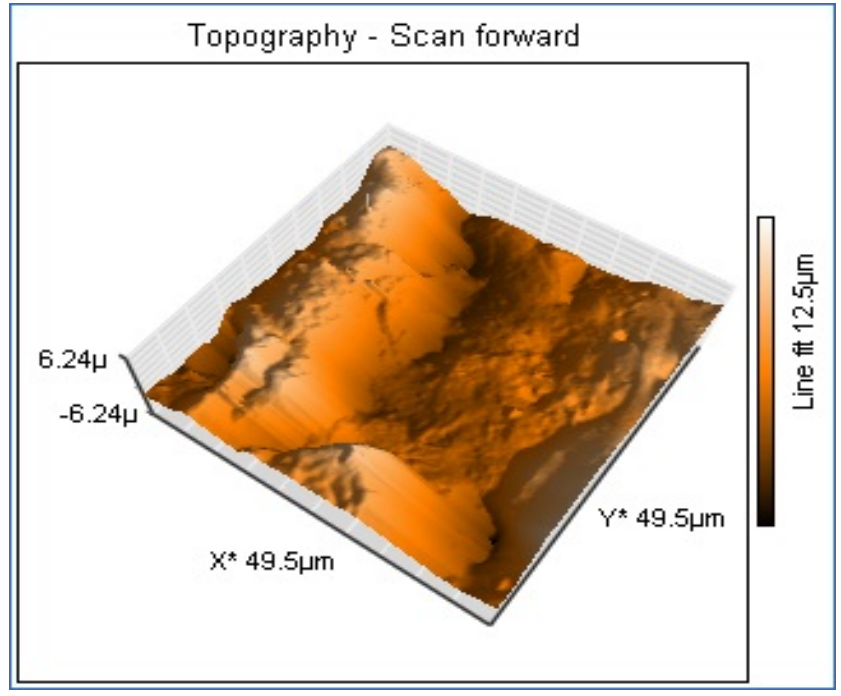

(b) 


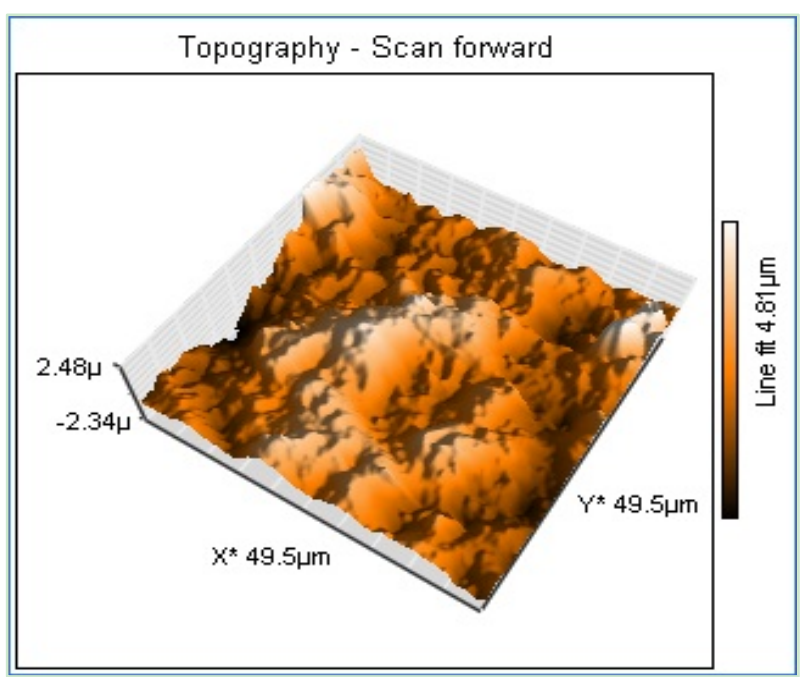

(c)

Figure 5. AFM micrographs of the surface roughness of (a) untreated Aluminum alloy 6082, (b) Aluminum alloy 6082, PEO treated at $150 \mathrm{~V}$ for $60 \mathrm{~min}$ in aqueous solution of $10 \mathrm{~g} / 1 \mathrm{NaAlO} 2$ and $5 \mathrm{~g} / \mathrm{l} \mathrm{KOH}$, (c) the treatment as (b) then PECVD treated for $60 \mathrm{~min}$ at $400^{\circ} \mathrm{C}$.

\subsection{Hardness of the Coatings}

The surface hardness of the coatings is shown in Figure 6. The precise measurement of hardness impressions on the cross-section of coating was not possible. As they often end to cracking of the layer [16].

As can be seen in Figure 6, the PEO treatment resulted in very hard surface oxide layers. However the contribution of hard layers to surface hardness depends on the thickness of the layers. At $100 \mathrm{~V}$ PEO treatments, the surface oxide layer was very thin and therefore the whole hardness value was low because it had a major contribution of the soft aluminum substrate. At higher voltages the surface oxide layer was thick enough to show a high hardness.

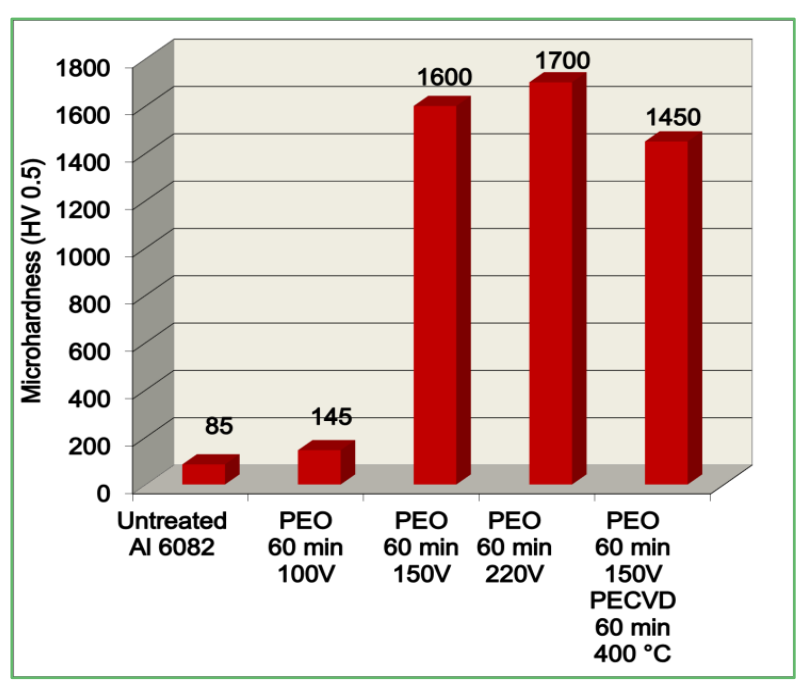

Figure 6. Surface microhardness of the samples treated with $\mathrm{PEO}$ coating for $60 \mathrm{~min}$ at different voltages in $10 \mathrm{~g} / \mathrm{l} \mathrm{NaAlO}$ and $5 \mathrm{~g} / \mathrm{l} \mathrm{KOH}$ and subsequent PECVD of TEOS for $60 \mathrm{~min}$ at $400 \mathrm{C}$.
The high hardness value is also related to the existence of hard $\alpha-\mathrm{Al}_{2} \mathrm{O}_{3}$ phase in the coating. Other investigations have shown that higher ratio of $\alpha$-alumina to $\gamma$-alumina in the coatings on aluminum alloy substrates leads to greater hardness.

As $\gamma-\mathrm{Al}_{2} \mathrm{O}_{3}$ phase has a low hardness of around $200 \mathrm{HV}$, it may be suggested that the main phase of the coatings in our investigations was composed of $\alpha-\mathrm{Al}_{2} \mathrm{O}_{3}$ [17].

It seems that PECVD treatment after PEO treatment has not varied the hardness value significantly. This is attributed to the very thin oxide layers resulting from PECVD treatment. From another hand, it has been observed that coatings with mullites phase or the coatings with silicon compounds show less hardness than coating without silicon. It has been shown that aluminum-silicon-oxygen compounds have a comparatively lower hardness value than that of pure aluminum oxide compounds [18].

\subsection{Friction Behaviour and Wear Loss}

The friction behaviour of untreated Al 6082 and the samples treated with PEO and PECVD treatments under 5 and $30 \mathrm{~N}$ derived from the ball-on-disc sliding wear tests are shown in Figure 7.

As can be observed in Figure 7a, the friction behaviour of untreated aluminium 6082 was quite varying. It seems that normal load of $5 \mathrm{~N}$ has not been enough to deform the oxide asperities and the steel slider has adhered intermittently with the surface that resulted in high varying friction behaviour.

However the same behaviour was observed under $30 \mathrm{~N}$ up to $30 \mathrm{~m}$ distance (Figure $7 \mathrm{~b}$ ). Afterwards the friction variations showed a typical stick-slip behavior that was highly repeatable. This behavior is strongly attributed to the repeated adhesion and separation of the steel slider with surface asperities of untreated aluminum alloy 6082 under normal load of $30 \mathrm{~N}$.

PEO treatment resulted also in high variation of friction behavior (Figure 7c). Under normal load of $5 \mathrm{~N}$, friction behavior was highly varying. The varying intervals were shorter than that of untreated sample and did not repeat regularly. The friction coefficient value under normal load of $30 \mathrm{~N}$ was high but the variations were less than that of $5 \mathrm{~N}$ load. The curve of $30 \mathrm{~N}$ load shows that the friction coefficients were high at the beginning, then after some fluctuation gradually decreased and remained constant with distance similar to that of $5 \mathrm{~N}$ loads.

The trend of the initial 'running in' stage in sliding wear test is due to the surface structure, roughness and adhesion between the pair of sliding components.

High surface roughness and granular and irregular coatings on the surface create a resistance against sliding and cause an increase in the coefficient of friction.

As can be seen in Figure 7, the mean coefficient of friction is at least 0.2 under $5 \mathrm{~N}$ load and increases to approximately 0.45 under normal load of $30 \mathrm{~N}$. This is mainly due to the higher normal load of $30 \mathrm{~N}$ if compared with that of $5 \mathrm{~N}$. 


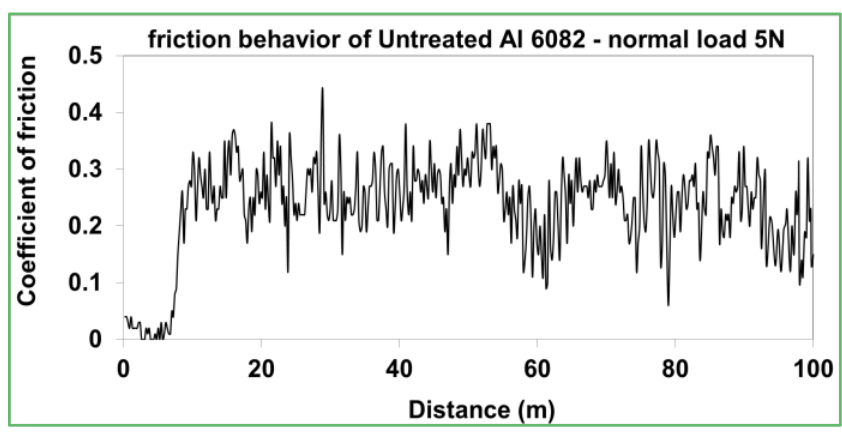

(a)

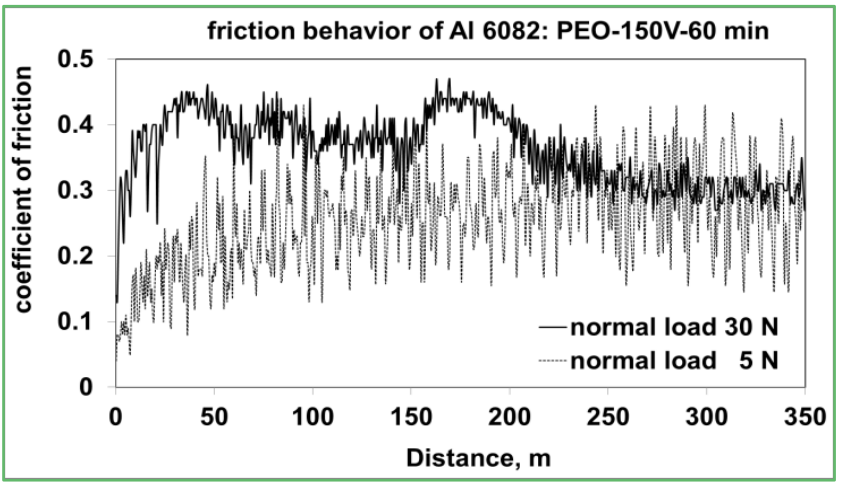

(c)

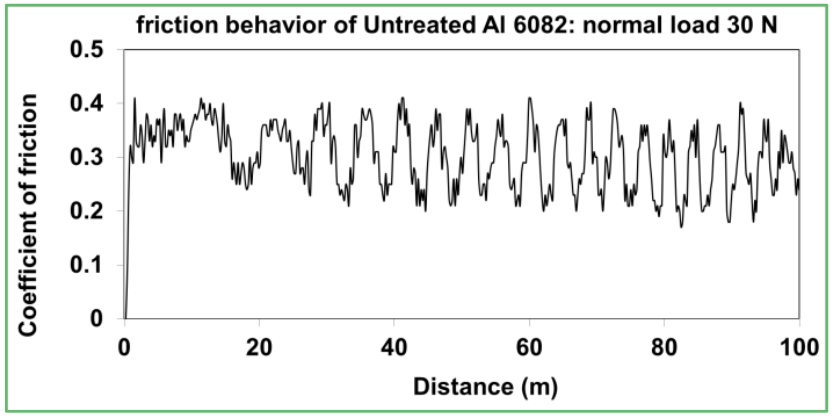

(b)

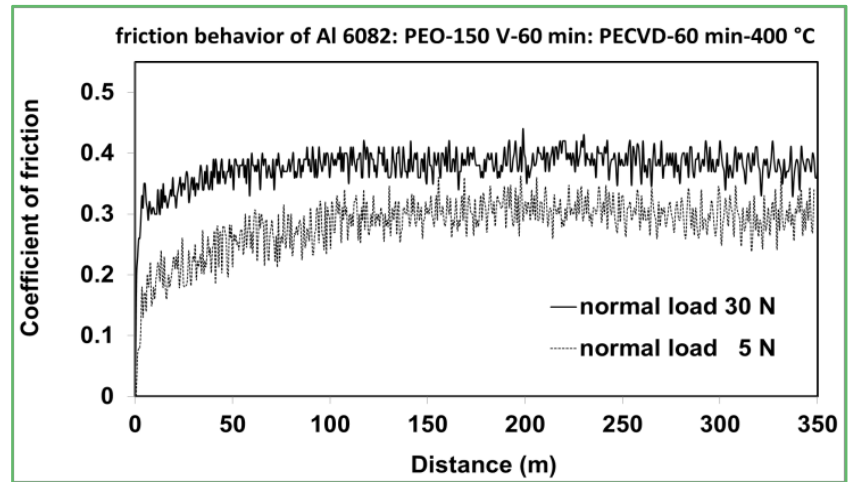

(d)

Figure 7. Friction behavior of untreated aluminum alloy 6082 under normal loads of (a) $5 \mathrm{~N}$, (b) $30 \mathrm{~N}$, (c) PEO coated surface at $150 \mathrm{~V}$ for 60 min in aqueous solution of $10 \mathrm{~g} / 1 \mathrm{NaAlO}_{2}$ and $5 \mathrm{~g} / 1 \mathrm{KOH}$ under normal load of 5 and $30 \mathrm{~N}$ and (d) PECVD treated surface by TEOS for $60 \mathrm{~min}$ at $400^{\circ} \mathrm{C}$ after PEO treatment under normal load of 5 and $30 \mathrm{~N}$.

In comparison with untreated surface, the friction behavior of PEO coated surface may be related to the weaker adherent junctions or less adhesion between the slider and PEO treated surface than those between slider and untreated material.

PEVCD treatment after PEO reduced the variation of friction coefficient significantly (Figure $7 \mathrm{~d}$ ). Under both 5 and $30 \mathrm{~N}$ loads the variation of friction coefficient reduced strongly. The average values of 0.25 and 0.35 can be estimated for the coefficients of friction under 5 and $30 \mathrm{~N}$ respectively. These are less than those for untreated and PEO treated surfaces. It may be proposed that PECVD of TEOS has reduced the adhesion between the slider and PECVD treated surface more than that of PEO coated surfaces [19]. The smoother friction behavior of this treatment resulted in less wear loss than other treatments.

The wear loss of the samples was examined under ball-on-disc configuration. The profiles of cross section of the wear scars are shown in Figure 8. These profiles produced using a DEKTAK surface profilometer which moved in the direction of the radius of circular wear tracks and passed the worn surface area. As can be seen in the Figure 8 , the depth of the wear track on untreated sample was much larger than that of other samples.

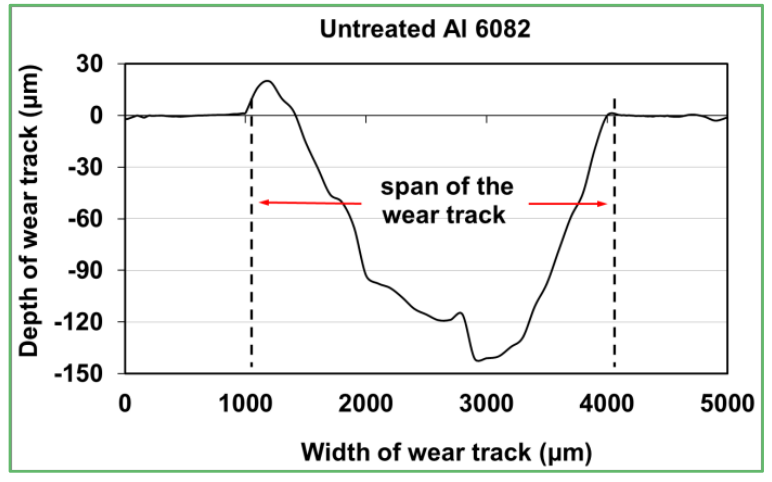

(a)

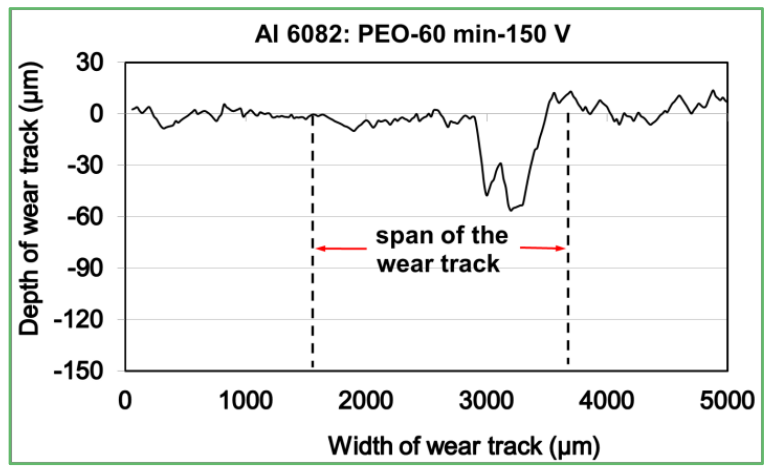

(b) 


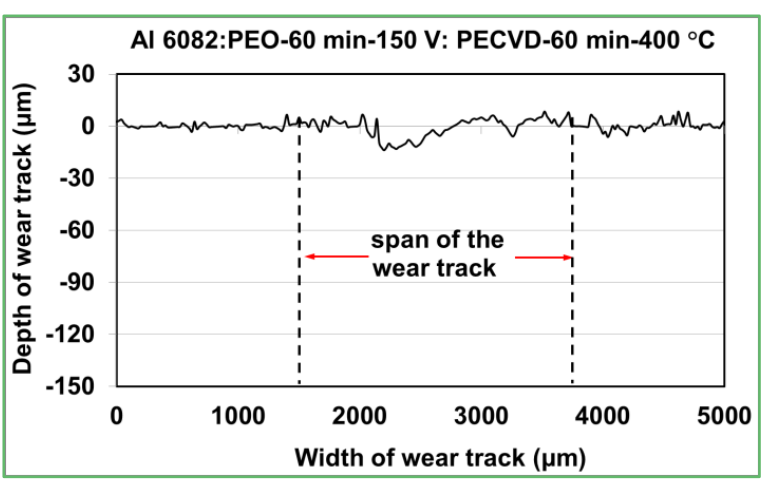

(c)

Figure 8. The profiles show the cross section of the wear tracks developed under normal load of $30 \mathrm{~N}$ on the surface of (a) untreated aluminum alloy 6082, (b) PEO coated sample at $150 \mathrm{~V}$ for $60 \mathrm{~min}$ in aqueous solution of 10 $\mathrm{g} / 1 \mathrm{NaAlO}_{2}$ and $5 \mathrm{~g} / \mathrm{KOH}$ and (c) the sample PECVD treated by TEOS for 60 min at $400^{\circ} \mathrm{C}$ after PEO treatment.

The low depth of wear track in PEO and PECVD treated surfaces is connected to a structural change in the coatings [20]. These coatings were strongly more wear resistant than that of untreated sample. The reason of this was due to the high content of $\alpha-\mathrm{Al}_{2} \mathrm{O}_{3}$ phase with high density and hardness on treated surfaces. However it seems that PEO treated wear track has worn in some parts deeper than other parts. While the PECVD treated surface had the same resistance to wear all over the wear track. The reaction of the samples against sliding was evaluated and represented in Figure 9.

Dry ball-on-disc wear tests were performed on Aluminum-alloy 6082 substrate, PEO treated sample and PECVD treated samples, under a normal load of $30 \mathrm{~N}, 0.1$ $\mathrm{m} / \mathrm{s}$ sliding speed for sliding distances up to $350 \mathrm{~m}$ and humidity of $50 \%$ RH against SAE 52100 bearing steel.

The lower wear loss of PEO sample is quite reasonable and is due to the $\alpha-\mathrm{Al}_{2} \mathrm{O}_{3}$ oxide layers that are hard and wear resistant [21]. In fact the low shear force that involved during sliding resulted from a hard surface cutting a soft counterpart [22].

The much lower wear loss of PECVD treated surface might be due to some reasons. It may be stated that some of the discharge channels got closed while some of them remained open during the PECVD treatment of PEO coated surface and provided a smother or less adhering surface.

The surface of the wear track is more flat and the sink-hole type structure more or less flattened out and merged into each other forming a more uniform surface (Figure 4d) [23]. The other reason may be the formation of a solid lubricant due to the introduction of silicon compounds to the surface.

In our results, the PECVD treated surface gives a smoother friction behavior if compared to $\mathrm{PEO}$ treated surface. This indicates that hard and soft rubbing pair generated lower friction and higher wear resistance on the surface.

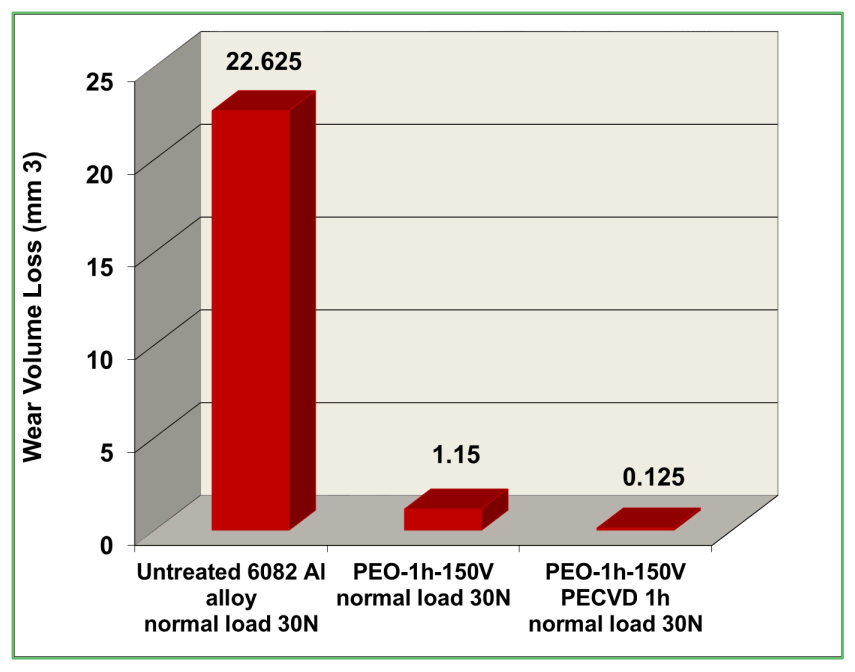

Figure 9. The bar graph shows the wear volume loss under normal load of $30 \mathrm{~N}$ for (a) untreated aluminum alloy 6082, (b) PEO treated sample at $150 \mathrm{~V}$ for $60 \mathrm{~min}$ in aqueous solution of $10 \mathrm{~g} / 1 \mathrm{NaAlO}_{2}$ and $5 \mathrm{~g} / \mathrm{KOH}$ and (c) the sample PECVD treated by TEOS for $60 \mathrm{~min}$ at $400^{\circ} \mathrm{C}$ after PEO treatment.

\section{Conclusions}

Aluminum alloy 6082 was plasma electrolytic oxidized (PEO) in $\mathrm{NaAlO}_{2}$ : $\mathrm{KOH}$ aqueous solution at different time and voltages.

According to an elementary investigation, it was observed that the reliable coating thicknesses did not increase significantly by voltages more than $150 \mathrm{~V}$ for $60 \mathrm{~min}$ in aqueous solution of $10 \mathrm{~g} / 1 \mathrm{NaAlO}_{2}$ and $5 \mathrm{~g} / \mathrm{KOH}$. Therefore friction and wear tests of the samples were compared at these conditions.

To achieve new surfaces, the PEO treated samples were deposited by Plasma Enhanced Chemical Vapor Deposition (PECVD) of TEOS, Ar and $\mathrm{O} 2$ for $60 \mathrm{~min}$ at $400^{\circ} \mathrm{C}$.

The microhardness of PEO treated surface was much higher than that of untreated aluminum alloy 6082. While the hardness of PECVD treated surface was slightly less than that of PEO coated surface.

Surface topography of PEO coated surfaces at $150 \mathrm{~V}$ was relatively smoother than those treated at other voltages. However PECVD treatment produced a relatively more uniform and smother surface.

Aluminum alloy 6082 showed a typical stick-slip behavior. The friction behavior of PEO coated surface was highly varying and increased if compared to that of untreated material. PECVD treatment decreased the variation and average value of friction coefficient.

The wear loss of PEO treated surface was 40 times less than that of untreated aluminum alloy 6082. PECVD treatment reduced the wear loss of PEO treated surface several times. 


\section{Acknowledgements}

The authors acknowledge Shahid Beheshti University in the Islamic republic of Iran for the financial support of this study.

\section{REFERENCES}

[1] A. L. Yerokhin, X. Nie, A. Leyland, A. Matthews, S. J. Dowey. Plasma electrolysis for surface engineering, Surf. Coat. Technol., Vol. 122, 73-93, 1999.

[2] C. B. Wei, X. B. Tian, S. Q. Yang, X. B. Wang, R. K. Y. Fu, P. K. Chu. Anode current effects in plasma electrolytic oxidation, Surf. Coat. Technol., Vol.201, 5021-5024. 2007.

[3] N. Parvini Ahmade, R. Khosroshahi and B.Baghal Asl, Deposition of oxide layers on aluminium via plasma Electrolysis method in Alkali Solutions by unipolar current system and study of its physical properties, Asian Journal of Applied Sciences, Vol. 2, No. 1, 74-82. 2009.

[4] L. O. Snizhko, A. L. Yerokhin, A.Pinkington, N. L. Gurevina, D. O. Misnyankin, A. Leyland, A. Matthews. Anodic processes in plasma electrolytic oxidation of aluminum in alkaline solutions, Electrochimica-Acta, Vol. 49, 2085-2095, 2004.

[5] W. C. Gu, G. H. Lv, H.Chen, G. L. Chen, W. R. Feng, S. Z. Yang. Characterisation of ceramic coatings produced by plasma electrolytic oxidation of aluminum alloy, Material Science and Engineering A, Vol. 447, 158-162, 2007.

[6] J. A. Curran, T. W. Clyne. Thermo-physical properties of plasma electrolytic oxide coatings on aluminum, Surface and Coating Technology, Vol. 199, 168-176, 2005.

[7] S. W. Byeon, K. J. Sik, G. K. Yeon, H. Bon. Characteristic of $\mathrm{AlON}-\mathrm{Al}_{2} \mathrm{O}_{3}$ coatings on Al6061 alloy by electrolytic plasma processing in aluminate and nitride electrolytes, Surface and Coatings Technology, Vol. 204, 3196-3199, 2010.

[8] I. A. Shareef, G. W. Rubloff, and W. N. Gill. Role of gas phase reactions in subatmospheric chemical-vapor deposition ozone/TEOS processes for oxide deposition, J. Vac. Sci. Technol. B, Vol. 14, No. 2, 772-774, 1996.

[9] C. E. Viana, A. N. R. da Silva, N. I. Morimoto, O. Bonnaud. Analysis of $\mathrm{SiO}_{2}$ Thin Films Deposited by PECVD Using an Oxygen-TEOS-Argon Mixture, Brazilian Journal of Physics, Vol.31, No. 2, 299-303, 2001.

[10] J. H. Lee, C. H. Jeong, J. T. Lim, N. G. Jo, S. J. Kyung, G. Y. Yeom. Characteristic of $\mathrm{SiO}_{2}$ Films Deposited by Using Low-Temperature PECVD with TEOS/ $\mathrm{N}_{2} / \mathrm{O}_{2}$, Journal of the Korean Physical Society, Vol.46, No. 4, 890-894. 2005.

[11] J. He, Q. Z. Cai, H. H. Luo, L. Yu, and B. K. Wei. Influence of silicon on growth process of plasma electrolytic oxidation coating on Al-Si alloy, Journal of Alloys and Compounds Vol. 471, 395-399, 2009.
[12] P. De Silva, K. Sagoe-Crenstil. The Effect of $\mathrm{Al}_{2} \mathrm{O}_{3}$ and $\mathrm{SiO} 2$ On Setting and Hardening of $\mathrm{Na}_{2} \mathrm{O}-\mathrm{Al}_{2} \mathrm{O}_{3}-\mathrm{SiO}_{2}-\mathrm{H}_{2} \mathrm{O}$ Geopolymer Systems, Journal of the Australian Ceramic Society Vol. 44, No. 1, 39-46, 2008.

[13] Y. J. Oh, J. I. Mun, J. H. Kim. Effects of alloying elements on microstructure and protective properties of $\mathrm{Al}_{2} \mathrm{O}_{3}$ coatings formed on aluminum alloy substrates by plasma electrolysis, Surface \& Coatings Technology, Vol. 204, 141148. 2009.

[14] Y. J. Guan, Y. Xia, and G. Li. Growth mechanism and corrosion behavior of ceramic coatings on aluminum produced by autocontrol AC pulse PEO, Surface and Coatings Technology, Vol. 202, 4602-4612, 2008.

[15] Y. Wang, Z. Jiang, X. Liu, Z. Yao, Influence of treating frequency on microstructure and properties of $\mathrm{Al}_{2} \mathrm{O}_{3}$ coating on 304 stainless steel by cathodic plasma electrolytic deposition, Applied Surface Science, Vol. 255, 8836-8840, 2009.

[16] X. Zhang, K.-S. Chen, R. Ghodsi, A. A. Ayon, S. M. Spearing. Residual stress and fracture in thick tetraethylorthosilicate (TEOS) and silane-based PECVD oxide films, sensors and Acutaors A, Vol. 91, 373-380, 2001.

[17] S. S. Byeon, K. J. Wang, Y. G. Koo, B. Heun. Characteristic of $\mathrm{AlON}-\mathrm{Al}_{2} \mathrm{O}_{3}$ coatings on Al6061 alloy by electrolytic plasma, processing in aluminate and nitride electrolytes, Surface and Coatings Technology, Vol. 204, 3196-3199, 2010.

[18] A. A. Voevdin, C. Rebholz, A. Matthews. Comparative Tribology Studies of Hard Ceramic and Composite Metal-DLC Coatings in Sliding Friction Conditions, " Tribology transactions, Vol. 4, No. 38, 829 - 836, 1995.

[19] K. Ravi Kumar, K. M. Mohanasundaram, G. Arumaikkannu, R. Subramanian. Analysis of parameters influencing wear and frictional behaviour of aluminium-fly ash composites, Tribology Transactions, Vol. 55, 723-729, 2012.

[20] A. Polat, M. Makaraci, M. Usta. Influence of sodium silicate concentration on structural and tribological properties of microarc oxidation coatings on 2017A aluminum alloy substrate, Journal of Alloys and Compounds, Vol. 504, 519526, 2010.

[21] X. Nie, A. Wilson, A. Leyland A. Matthews. Deposition of duplex Al O DLC coatings on Al alloys for tribological applications using a combined micro-arc oxidation and plasma-immersion ion implantation technique, Surface and Coatings Technology, Vol. 121, 506-513. (2000),

[22] S. P. Sahu, A. Satapathy, D. Mishra, A. Patnaik, K. P. Sreekumar. Tribo-Performance Analysis of Fly AshAluminum Coatings Using Experimental Design and ANN, Tribology Transactions, Vol. 53, 533-542, 2010.

[23] J. Baxi, P. Kar, H. Liang, A. Polat, M. Usta, A. H. Ucisik, "Tribological characterization of microarc oxidized alumina coatings for biological applications, Vacuum, Vol. 83, 217-222, 2009. 